\title{
Pneumocystis jirovecii pneumonia prophylaxis for HIV-exposed neonates
}

\author{
This article was published in the following Dove Press journal: \\ Research and Reports in Neonatology \\ 8 April 2014 \\ Number of times this article has been viewed
}

\author{
Nicholas J Bennett \\ Division of Infectious Diseases \\ and Immunology, Connecticut \\ Childrens Medical Center, \\ Hartford, CT, USA
}

Correspondence: Nicholas J Bennett Connecticut Childrens Medical Center, 282 Washington Street, Hartford, CT, USA Tel + I 8605459490

Email nbennett0I@connecticutchildrens. org

\begin{abstract}
Pneumocystis pneumonia (PCP) is a common, usually fatal opportunistic infection of HIV-infected infants. This review summarizes the current knowledge and recommended practices regarding PCP prophylaxis in HIV-exposed infants. The incidence of PCP has dropped dramatically in areas of the world where widespread testing for HIV and empiric prophylaxis for PCP in HIV-exposed neonates have been adopted. The recommended drug for PCP prophylaxis is trimethoprim-sulfamethoxazole (TMP-SMX), and all HIV-infected infants under a year of age should receive PCP prophylaxis as well as combination anti-retroviral therapy. With the advent of accurate, timely testing that can reliably rule out infection with HIV at an early age, PCP prophylaxis can be safely avoided in the majority of HIV-exposed infants. Resource-poor settings should employ universal PCP prophylaxis for HIV-exposed infants and have a need for rapid, accurate, molecular testing approaches to diagnose HIV infection in exposed neonates.
\end{abstract}

Keywords: pneumocystis, jirovecii, PCP, HIV, prophylaxis, neonate

\section{Background}

Pneumocystis jirovecii (previously known as Pneumocystis carinii) is a single-celled fungal organism, previously (and erroneously) classified as a protozoa. ${ }^{1,2}$ It is unusual as a fungus in that it is resistant to many of the typical antifungal agents, but responds to treatment with some anti-protozoal agents. Pneumocystis is a ubiquitous organism with frequent detection at autopsy. ${ }^{3}$ Serologic studies have demonstrated gradual acquisition of antibodies to Pneumocystis through childhood in the absence of disease or risk factors for Pneumocystis pneumonia (PCP). ${ }^{4}$ Disease from Pneumocystis occurs in the setting of immune suppression, whether from prematurity, malnutrition, congenital, or acquired immune deficiencies.

Historically, PCP was seen in the setting of premature infants or children receiving chemotherapy for hematologic malignancies. Awareness regarding the disease rose significantly with the arrival of HIV, and the AIDS epidemic. PCP was one of the first opportunistic infections recognized as being characteristic of this new form of immune deficiency in the early $1980 \mathrm{~s},{ }^{5}$ and remains a significant problem even in the era of combination antiretroviral therapy (cART). PCP in infants born to HIVinfected mothers has been reduced by $95 \%$ with the awareness of the need for early treatment of perinatally acquired HIV infection, and simultaneous prophylaxis for PCP. ${ }^{6}$ Pre-HAART (highly active antiretroviral therapy) and the widespread use of trimethoprim-sulfamethoxazole (TMP-SMX) as prophylaxis in HIV-infected children Pneumocystis accounted for more than a third of the opportunistic infections reported 
in the Perinatal AIDS Collaborative Transmission Study and was the most prevalent infection seen. ${ }^{6}$

\section{Organism}

$P$. jirovecii is a small, unicellular fungus that exists in two morphologic forms. There are trophozoites that are about 1-5 $\mu \mathrm{m}$ in diameter, and larger cysts that may contain up to eight small intracystic bodies. The cysts are about 5-7 $\mu \mathrm{m}$ in diameter.

It is unclear how the organism is spread but airborne transmission is the most likely and is supported by animal models $;^{7}$ there is some evidence to support transplacental transmission. Despite this, because disease only occurs in the setting of severe immune suppression and because exposure to pneumocystis is ubiquitous, there are no strong recommendations on isolation of patients with PCP. Having said that, a patient with PCP should probably not share a room with another immunocompromised person. ${ }^{8,9}$

\section{Pathophysiology}

PCP occurs in the setting of impaired host immunity, when the organism replicates to high numbers in the alveolae and smaller airways, leading to significantly impaired gas exchange. Hypoxia is a common clinical finding, and is often out of proportion to other, more typical findings of pediatric pneumonia, such as fever, cough, and respiratory distress (although fever and tachypnea are also common). The inflammatory response includes the production of a proteinaceous exudate and macrophage infiltration. Foamy alveolar casts are a pathognomonic finding. Untreated, there is a progressive deterioration over days to weeks, leading to severe hypoxemia, respiratory failure, and death.

\section{Diagnosis of PCP}

The identification of Pneumocystis organisms in pulmonary specimens is considered diagnostic of PCP, along with typical histologic findings of foamy alveolar casts. Silver stains, PCR or immunohistological techniques have all been employed to diagnose PCP. In general, sputum is considered a poorly sensitive specimen and is difficult to obtain in children. Induced sputum obtained through the use of inhaled hypertonic saline has a sensitivity of only $50 \%$ and routine sputum specimens are probably wholly inadequate for diagnosis. Invasive specimens obtained from bronchoalveolar lavage are ideal and sensitivity may reach as high as $97 \% .^{10,11}$ Organisms may be seen for several days after starting therapy. ${ }^{12}$ It may be that gastric aspirates are a reasonable surrogate site for detection of Pneumocystis organisms but this is not considered a reasonable alternative at the present time. Serology is unhelpful due to the ubiquitous nature of Pneumocystis. The cell wall antigen 1-3 beta-D-glucan (BDG) can be used as a surrogate marker for possible PCP but the sensitivity and specificity in this setting have not been well assessed. ${ }^{13,14}$ Other fungal organisms will also cause positive 1-3 BDG tests.

\section{HIV infection - diagnosis}

The role of prophylaxis for PCP in the HIV-exposed neonate depends on the risk of acquiring HIV from their mother. In many HIV-exposed neonates in whom HIV can be adequately ruled out, PCP prophylaxis may not be necessary, but this depends on access to reliable testing.

The diagnosis of HIV infection in the neonate is complicated by the fact that maternally derived antibodies will cross the placenta and result in a positive HIV serologic test in every HIV-exposed newborn (the exception being if the mother was in the "window phase" of seroconversion). Diagnosis of HIV infection therefore relies on the use of polymerase chain reaction (PCR)-based assays. DNA-PCR is preferred, which detects the integrated HIV provirus in peripheral blood mononuclear cells. Reverse-transcriptase PCR of viral RNA in virions in the plasma is an alternative, and may be more sensitive at detecting non-B clade HIV infections. However, because infants born to HIV-infected mothers will generally be on antiviral prophylaxis, an RNA viral load assay may be negative and falsely reassuring.

Assays that detect HIV using p24 antigenemia are insensitive, and viral culture is protracted and expensive neither test is recommended in the setting of diagnosing a neonate with HIV.

A typical test algorithm is an initial test at birth, followed by additional testing at 4 weeks, 2 months, and 4 months of life. Testing at birth will detect the unusual situation of in utero HIV infection, which would necessitate immediate treatment with cART. Testing at 4 weeks of age (providing one prior test is also negative) can presumptively rule out HIV infection. ${ }^{15}$ Specific guidelines vary by locality but most experts would consider a final negative DNA PCR after 4 months of age as being definitive proof of no HIV infection.

Serology in a perinatally exposed infant may not revert to HIV-negative until 12 months of age, or sometimes even older. Testing of HIV antibodies is often performed in HIV-exposed infants after a year of age in order to document seroreversion although it is not required to rule out infection. 


\section{Timing of PCP prophylaxis}

Unlike the decision to initiate prophylaxis in adults or older children infected with HIV, the laboratory markers of CD4+ T-cell count or percentage are unhelpful in assessing the risk of PCP in infants. All HIV-infected children under 12 months of age should receive prophylaxis for PCP, with the exception of the immediate neonatal period. ${ }^{16,17}$

The drug of choice for PCP prophylaxis, TMP-SMX, is not recommended for use in infants under 28 days of age due to the risk of kernicterus. In addition, there is the possibility of additive hematologic toxicity when administered with zidovudine (ZDV) for the first 4 to 6 weeks after perinatal exposure. Despite these limitations, PCP prophylaxis should be initiated as soon as possible in children for whom HIV infection cannot be considered adequately ruled out. If two negative DNA PCRs are available before the discontinuation of ZDV at 6 weeks of age, then many practitioners would consider this reassuring enough, even though additional DNA PCR tests would be obtained through to 4 months of age. Current guidelines support the decision to withhold PCP prophylaxis in those infants in whom HIV infection has been presumptively ruled out by two negative DNA PCR assays, with the second being at 4 weeks of age. ${ }^{16,17}$ Therefore, infants in this situation may not ever begin PCP prophylaxis, depending on local practices and the availability of timely, accurate diagnostic testing. If two negative HIV DNA PCR tests cannot be obtained by 4-6 weeks of age then TMP-SMX should be started and continued until HIV infection can be definitively ruled out. A more cautious approach would be to initiate PCP prophylaxis on all HIVexposed neonates immediately after discontinuing ZDV monotherapy through the final DNA PCR after 4 months of age. The dose of TMP-SMX when used for PCP prophylaxis is $150 \mathrm{mg} / \mathrm{m}^{2} /$ day of trimethoprim component, divided once or twice a day for 3 consecutive days in a week, or on alternate days 3 times a week.

If HIV infection is confirmed in an exposed infant, then PCP prophylaxis should be started after a month of age and continued through the first year of life regardless of viral load, CD4+ T-cell numbers or treatment regimen. After 12 months of age the child should be reassessed and PCP prophylaxis continued if needed, based on immunologic markers. The recommendations discussed here are summarized in Table 1.

Alternative options for PCP prophylaxis include dapsone, atovaquone, and pentamidine. None are recommended for neonates, and pentamidine (generally administered in a nebulized inhaled form) may be problematic in young children. Dapsone is similar to TMP-SMX in that it is associated with
Table I When to initiate or discontinue Pneumocystis pneumonia prophylaxis in HIV-exposed neonates

\begin{tabular}{ll}
\hline HIV test results & Timing of prophylaxis \\
\hline HIV infection confirmed at birth or & Begin at 4-6 weeks of age \\
in first 4-6 weeks of life & \\
HIV infection not adequately ruled & Begin at 4-6 weeks of age \\
out by 4-6 weeks of age & \\
HIV infection presumptively ruled & Prophylaxis may not be necessary \\
out by 4-6 weeks of age & (practices may vary) \\
HIV infection definitively ruled out & Prophylaxis may be discontinued. \\
by 4-6 months of age & \\
\hline
\end{tabular}

hematologic abnormalities and hyperbilirubinemia and also requires testing for glucose-6-phosphate dehydrogenase deficiency. It is dosed at $2 \mathrm{mg} / \mathrm{kg}$ once daily, or $4 \mathrm{mg} / \mathrm{kg}$ once weekly. Atovaquone is another option, similarly not approved for use under a month of age in preventing PCP, dosed at $30 \mathrm{mg} / \mathrm{kg}$ once daily.

The criteria for discontinuing PCP prophylaxis after a year of age are beyond the scope of this article, and the reader is referred to the most recent Centers for Disease Control guidelines on the management and prevention of opportunistic infections in infants and children with HIV infection. ${ }^{16}$

\section{Future directions}

The approach to prevention of PCP has remained relatively unchanged since TMP-SMX was established as the drug of choice. Universal prophylaxis for PCP in HIV-exposed neonates is already no longer recommended assuming early, accurate HIV testing can be performed to presumptively rule out HIV infection. There have been advances in diagnosis of PCP itself with the use of PCR assays but it seems unlikely that these will factor into the area of prophylaxis. It would not likely be prudent to discontinue or avoid PCP prophylaxis in HIV-infected infants even if they, or their household contacts, tested negative for Pneumocystis due to the invasive nature of current testing modalities, but also due to the ubiquitous nature of the organism.

What is clear is that in resource-poor settings without state-of-the-art testing available for HIV, PCP prophylaxis should be initiated universally on HIV-exposed neonates. A large cohort of HIV-infected babies from the Ukraine showed low rates of TMP-SMX utilization despite formal recommendations for universal use. PCP was the most frequent opportunistic infection reported, in $27 \%$ of the cases of AIDS, but TMP-SMX had not been administered to $90 \%$ of those who had PCP or other bacterial infection, and had only been given to $29 \%$ of all infected infants. ${ }^{18}$ Efforts should continue to be made to ensure timely access to effective antiretroviral 
therapy as well as PCP prophylaxis to all HIV-infected infants around the globe. Hand in hand with this is the need for accurate HIV diagnostic testing. The development of molecular testing kits that can be readily applied to resource-poor settings will help tremendously with the appropriate utilization of resources toward HIV-infected infants. ${ }^{19}$

\section{Summary}

Prophylaxis for PCP in HIV-exposed and HIV-infected infants generally applies to babies beyond the immediate neonatal period. The drug of choice is TMP-SMX, dosed at $150 \mathrm{mg} / \mathrm{m}^{2} /$ day 3 days a week. In infants in whom HIVinfection can be presumptively or definitively ruled out, PCP prophylaxis may be safely omitted or discontinued. Once HIV infection is confirmed, immediate treatment for HIV with cART is indicated, and PCP prophylaxis should be continued through at least the first year of life. Future efforts in this arena should be focused toward extending the clear benefits of early diagnosis and treatment seen in the developed world to other countries.

\section{Disclosure}

The author has no conflicts of interest to report in this work.

\section{References}

1. Stringer JR, Beard CB, Miller RF, Wakefield AE. A new name (Pneumocystis jiroveci) for Pneumocystis from humans. Emerg Infect Dis. 2002;8(9):891-896.

2. Edman JC, Kovacs JA, Masur H, Santi DV, Elwood HJ, Sogin ML. Ribosomal RNA sequence shows Pneumocystis carinii to be a member of the fungi. Nature. 1988;334(6182):519-522.

3. Ponce CA, Gallo M, Bustamante R, Vargas SL. Pneumocystis colonization is highly prevalent in the autopsied lungs of the general population. Clin Infect Dis. 2010;50(3):347-353.

4. Pifer LL, Hughes WT, Stagno S, Woods D. Pneumocystis carinii infection: evidence for high prevalence in normal and immunosuppressed children. Pediatrics. 1978;61(1):35-41.

5. Centers for Disease Control (CDC). Pneumocystis pneumonia - Los Angeles. MMWR. 1981;5;30(21):250-252.

6. Nesheim SR, Kapogiannis BG, Soe MM, et al. Trends in opportunistic infections in the pre- and post-highly active antiretroviral therapy eras among HIV-infected children in the Perinatal AIDS Collaborative Transmission Study, 1986-2004. Pediatrics. 2007;120:100-109.
7. Menotti J, Emmanuel A, Bouchekouk C, et al. Evidence of airborne excretion of Pneumocystis carinii during infection in immunocompetent rats. Lung involvement and antibody response. PLoS One. 2013;8(4): e62155.

8. Schmoldt S, Schuhegger R, Wendler T, et al. Molecular evidence of nosocomial Pneumocystis jirovecii transmission among 16 patients after kidney transplantation. J Clin Microbiol. 2008;46(3):966-971.

9. de Boer MG, Bruijnesteijn van Coppenraet LE, Gaasbeek A, et al. An outbreak of Pneumocystis jiroveci pneumonia with 1 predominant genotype among renal transplant recipients: interhuman transmission or a common environmental source? Clin Infect Dis. 2007;44(9):1143-1149.

10. Bigby TD. Diagnosis of Pneumocystis carinii pneumonia. How invasive? Chest. 1994;105(3):650-652.

11. Shelhamer JH, Gill VJ, Quinn TC, et al. The laboratory evaluation of opportunistic pulmonary infections. Ann Intern Med. 1996;124(6): 585-599.

12. Roger PM, Vandenbos F, Pugliese P, et al. Persistence of Pneumocystis carinii after effective treatment of $P$. carinii pneumonia is not related to relapse or survival among patients infected with human immunodeficiency virus. Clin Infect Dis. 1998;26:509-510.

13. Pisculli ML, Sax PE. Use of a serum beta-glucan assay for diagnosis of HIV-related Pneumocystis jiroveci pneumonia in patients with negative microscopic examination results. Clin Infect Dis. 2008;46(12): 1928-1930.

14. Desmet S, Van Wijngaerden E, Maertens J, et al. Serum (1-3)-beta-Dglucan as a tool for diagnosis of Pneumocystis jirovecii pneumonia in patients with human immunodeficiency virus infection or hematological malignancy. J Clin Microbiol. 2009;47(12):3871-3874.

15. Read JS; Committee on Pediatric AIDS, American Academy of Pediatrics. Diagnosis of HIV-1 infection in children younger than 18 months in the United States. Pediatrics. 2007;120(6):e1547-e1562.

16. Panel on Opportunistic Infections in HIV-Exposed and HIV-Infected Children.Guidelines for the Prevention and Treatment of Opportunistic Infections in HIV-Exposed and HIV-Infected Children. Department of Health and Human Services. Available at http://aidsinfo.nih.gov/ contentfiles/lvguidelines/oi_guidelines_pediatrics.pdf. Accessed February 20, 2014.

17. Centers for Disease Control. Guidelines for prophylaxis against Pneumocystis carinii pneumonia for children infected with human immunodeficiency virus. MMWR. 1991;40(No RR-2).

18. Mahdavi S, Malyuta R, Semenenko I, Pilipenko T, Thorne C. Ukraine European Collaborative Study Group. Treatment and disease progression in a birth cohort of vertically HIV-1 infected children in Ukraine. BMC Pediatr. 2010;10:85.

19. Choudhary I, Chimanpure V, Patil A, Mukhopadhyaya R, Paranjape R, Bhattacharya J. Single step detection of HIV-1 proviral DNA and housekeeping $\beta$-actin gene from dried blood spots by a monoplex polymerase chain reaction. J Virol Methods. 2013;187(1): 203-206. open access journal publishing original research, reports, editorials, reviews and commentaries on neonatal health. The manuscript management system is completely online and includes a very quick and fair

\section{Dovepress}

peer-review system. Visit http://www.dovepress.com/testimonials.php to read real quotes from published authors. 